\title{
A multicenter, prospective, observational study of the long-term outcomes of Crohn's disease patients under routine care management in Greece
}

\author{
Spyridon Michopoulos a, Gregorios Paspatis ${ }^{b}$, Konstantinos Triantafyllouc, Spyridon Potamianos ${ }^{d}$, \\ Vassiliki Nikolopoulou ${ }^{e}$, Evangelos Akriviadisf, John A. Karagiannis ${ }^{9}$, Spyridon Ladash ${ }^{\mathrm{h}}$, Maria \\ Tampaki', Charalambos Tzathas'†
}

Alexandra General Hospital of Athens; Venizeleio Pananeio General Hospital of Heraklion, Crete; Medical School, National and Kapodistrian University of Athens, "Attikon” University General Hospital, Athens; General Hospital of Larissa; University General Hospital of Patras; Diavalkaniko Medical Center of Thessaloniki; "Konstantopouleio-Agia Olga" General Hospital of Nea Ionia, Athens; Laiko General Hospital of Athens; Merck Sharp \& Dohme Pharmaceutical, Industrial and Commercial S.A, Athens; Tzaneio General Hospital of Piraeus, Piraeus, Greece

Abstract
Background Real-world data on management patterns and long-term outcomes of patients with inadequately controlled Crohn's disease (CD) in Greece are scarce.

Methods This was a multicenter, prospective observational study of 18-65-year-old CD patients whose physicians judged that their current therapy was inadequate to control their condition and therefore decided to switch treatment. Data were collected at enrollment (time of switch), and 30, 54 and 104 weeks post-enrollment.

Results Sixty-six eligible patients (median age: 35.8 years; $56.1 \%$ males; median CD diagnosis duration: 2.3 years) were enrolled by nine hospital sites. At the time of treatment switch, $66.7 \%$ had

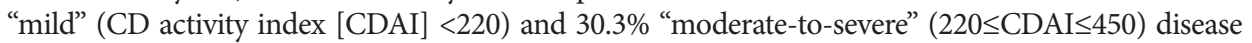
activity. Ileocolonic involvement, extraintestinal manifestations, prior CD-related surgeries and prior corticosteroid use were reported in $65.2 \%, 51.5 \%, 24.2 \%$ and $78.8 \%$ of patients, respectively. Throughout the study, most patients were managed with anti-tumor necrosis factor (TNF) medications (74.2\%/74.1\% infliximab; 10.6\%/13.8\% adalimumab at enrollment/end of study, respectively). At 54 and 104 weeks post-enrollment, the baseline CDAI score (median 174.5) decreased to 145.5 and 146.0 points $(\mathrm{P}<0.001)$ and the baseline $\mathrm{C}$-reactive protein level (median: $13.6 \mathrm{mg} / \mathrm{L}$ ) decreased to 3.5 and $3.0 \mathrm{mg} / \mathrm{L}(\mathrm{P}<0.001)$, respectively, not differing statistically between patients with "mild" and "moderateto-severe" disease activity. In this patient population, $56.1 \%$ were corticosteroid-free throughout observation, while for the remaining $43.9 \%$, the mean percentage corticosteroid-free period was $80.2 \%$. CD-related surgeries and hospitalizations were reported in $8.1 \%$ and $19.4 \%$, respectively.

Conclusion Under routine care in Greece, inadequately controlled CD patients were mainly switched to anti-TNFs, which lowered disease activity and reduced corticosteroid use.

Keywords Crohn's disease, CDAI, corticosteroids, hospitalizations, anti-TNF

Ann Gastroenterol 2018; 31 (5): 1-10

\footnotetext{
"Gastroenterology Department, "Alexandra” General Hospital of Athens (Spyridon Michopoulos); bastroenterology Department, "Venizeleio Pananeio" General Hospital of Heraklion, Crete (Gregorios Paspatis); cHepatogastroenterology Unit, Second Department of Internal Medicine - Propaedeutic, Research Institute and Diabetes Center, Medical School, National and Kapodistrian University of Athens, "Attikon" University General Hospital, Athens (Konstantinos Triantafyllou); ${ }^{\mathrm{d}}$ Gastroenterology Department, University General Hospital of Larissa (Spyridon Potamianos); ${ }^{\mathrm{G} G a s t r o e n t e r o l o g y ~ D e p a r t m e n t, ~ U n i v e r s i t y ~ G e n e r a l ~ H o s p i t a l ~ o f ~ P a t r a s, ~ R i o ~(V a s s i l i k i ~}$ Nikolopoulou); $3^{\text {rd }}$ Internal Medicine Department, "Diavalkaniko" Medical Center of Thessaloniki, Thessaloniki (Evangelos Akriviadis); "Bastroenterology Department, "Konstantopouleio-Agia Olga" General Hospital of Nea Ionia, Athens (John A. Karagiannis $\uparrow$ ); $;$ First Propaedeutic Clinic of Internal Medicine, "Laiko" General Hospital of Athens (Spyridon Ladas); 'Merck Sharp \& Dohme Pharmaceutical, Industrial and Commercial S.A., Athens (Maria Tampaki); ${ }^{j}$ Gastroenterology Department, "Tzaneio" General Hospital of Piraeus, Piraeus (Charalambos Tzathas), Greece

Conflict of Interest: The study was sponsored by MSD Hellas

Corresponding author: Spyridon Michopoulos, 6 Aghias Kyriakis St., 14561 Athens, Greece, e-mail: michosp5@gmail.com

Received 8 January 2018; accepted 12 June 2018; published online 20 July 2018

DOI: https://doi.org/10.20524/aog.2018.0295
}

\section{Introduction}

Crohn's disease (CD) is a multifactorial, chronic, idiopathic, inflammatory bowel disease characterized by severe inflammation of the gastrointestinal tract. Uncontrolled inflammation may give rise to penetrating or stricturing complications necessitating hospitalization or surgery. Corticosteroids and immunosuppressive agents (azathioprine, mercaptopurine, and methotrexate) are the commonly used conventional treatments for CD [1]. For patients not responding or intolerant to conventional therapies, biologic therapies, mainly encompassing inhibitors of tumor necrosis factor a (TNFa) (infliximab, adalimumab and certolizumab pegol), may be offered [2-4]. 
An estimated $20-40 \%$ of CD patients are burdened by extraintestinal manifestations (EIMs), which may present either prior to or concurrently with the appearance of gastrointestinal symptoms, or even after an intestinal resection [5]. The most common EIMs affect the musculoskeletal, mucocutaneous and ocular systems, while the EIM rate appears to increase with disease duration $[5,6]$. With regard to surgeries, although declining rates have been reported over the last decades, a substantial proportion of CD patients still undergo at least one surgery during their disease course. Specifically, the surgery rates in the 2010 European Crohn's and Colitis Organisation (ECCO)-EpiCom cohort were estimated to be $10-35 \%$, $21-59 \%$, and $37-61 \%$ at 1,5 and 10 years post-diagnosis, respectively [5]. In the same study, the 10-year hospitalization rate was estimated to be 53\% [5], which alongside the EIM and surgery rates underscores the substantial burden of the disease.

At the time of study planning, data regarding the epidemiological characteristics of $\mathrm{CD}$ patients in Greece were limited to studies conducted at a local level, not allowing for a general appraisal of the patients' disease profile throughout the country [7-11]. CD is widely perceived as being of milder severity among Greek patients compared to the general European population, with lower reported rates of perianal involvement, need for surgery and development of cancer [9-11], although this claim is not supported across all published studies [8]. In light of the above concerns, the present study aimed to provide real-world data regarding the management and long-term outcomes of CD patients across Greece whose physicians judged that their current therapy was inadequate to control their condition and therefore decided to switch treatment.

\section{Patients and methods}

\section{Study objectives}

The study primarily aimed to evaluate the therapeutic modalities employed among inadequately controlled outpatients with "mild" (defined as CD activity index [CDAI] $<220)$ or "moderate-to-severe" $(220 \leq \mathrm{CDAI} \leq 450)$ disease activity, who were attending referral hospital centers for routine care, and to measure their response to treatment. Secondarily, the study aimed to evaluate the CD-related surgery and hospitalization rates over the 2-year follow-up period.

\section{Study design, population and setting}

This was a multicenter, prospective observational study, carried out in nine referral centers for inflammatory bowel disease (IBD) from representative geographic regions of Greece. Patients attending the study sites were enrolled consecutively to control and minimize patient selection bias. The eligible study population comprised males and females, 18-65 years of age, with active CD, irrespective of disease severity, whose physicians judged that their current therapy was inadequate to control their condition and therefore decided to switch treatment. Elderly patients were excluded from our study population because the management of CD in these patients is complicated by comorbidities, polypharmacy and surgical candidacy criteria, which could have confounded the outcomes of the study. Visits occurred at enrollment (time of treatment switch; Visit 1), and at 30 (Visit 2), 54 (Visit 3) and 104 (Visit 4) weeks post-enrollment. Data collected pertained to $\mathrm{CD}$ history, prior therapies, prior $\mathrm{CD}$-related surgeries, comorbidities, endoscopic assessments/mucosal healing, CDAI score, relevant inflammatory biomarkers (C-reactive protein $[\mathrm{CRP}]$, erythrocyte sedimentation rate [ESR]), CD management throughout the study, and CD-related surgeries and hospitalizations. The decision regarding the treatment regimen administered to the patients during the "switch" was not standardized but was based on the physician's current medical practice, independently of the decision to enroll the patient in the study.

The study was designed and conducted in accordance with the ethical principles of the Declaration of Helsinki and all national standing regulations. The study protocol and the final version of the patient's Informed Consent Form were reviewed and approved by the competent institutional review boards of the participating sites.

\section{Statistical analysis}

All analyses were performed in the set of eligible patients with available data. The Clopper-Pearson 95\% exact confidence intervals (CIs) were calculated for the percentages of patients with "mild" (i.e., CDAI<220), "moderate-to-severe" $(220 \leq \mathrm{CDAI} \leq 450)$, and "severe" (CDAI $>450)$ disease activity. The association between independent categorical variables was assessed with Fisher's exact test and logistic regression analysis. McNemar's test was used for comparison of paired categorical data. Significant differences in continuous variables were examined using the $t$-test or the Mann-Whitney $U$ test for two independent groups, and the Kruskal-Wallis test in cases with more than two independent groups. Changes in CDAI values from baseline to the post-enrollment visits were evaluated with the Wilcoxon signed-rank test. Disease-related hospitalization and surgery rates per patient-year were calculated using aggregate patient-time at risk as the denominator. Univariate negative binomial regression analysis (estimating the incidence rate ratio) was applied to assess the association of the hospitalization rates with factors of interest. All statistical tests were two-sided and were performed at a significance level of 0.05 . The statistical analysis was performed using $\mathrm{SAS}^{\varpi} \mathrm{v} 9.3$ (SAS Institute, Cary, NC).

The sample size estimation of 100 subjects was based on an anticipated proportion of $14 \pm 7 \%$ (95\%CI 7.20-20.8; $\alpha=0.05$ ) of "moderate-to-severe" CD patients (defined as CDAI 220450 at enrollment) in Greece, a country in which the disease is considered to have a milder course [9-11]. Based on the above, the inclusion of 100 patients was considered adequate to provide a representative picture of the disease severity in Greek CD patients, as well as of the treatment patterns and the associated outcomes. 


\section{Results}

\section{Patient characteristics}

Between 30 November, 2011, and 28 December, 2012, 71 patients were enrolled in the study by 9 hospital sites distributed across Greece. Sixty-six patients fulfilled all inclusion and exclusion criteria (Fig. 1). Approximately half of the eligible patients $(51.5 \% ; 34 / 66)$ were enrolled from 5 study sites located in Attica, while the remaining 48.5\% (32/66) were enrolled by study sites located in Thessaly, Crete, Western Greece and Central Macedonia. The overall study duration was 3.2 years, with the last patient's final visit occurring on 24 January 2015. It is worth noting that the evaluable patient population $(n=66)$ was lower than the planned sample of 100 patients (see Limitations, below).

Sociodemographic, anthropometric and clinical characteristics of the study population are displayed in Table 1. All but one of the participants were Caucasian (98.5\%; $65 / 66$ ) and $56.1 \%$ were males. The patients' median age at enrollment was 35.8 years and their body mass index (BMI) was $23.2 \pm 3.9 \mathrm{~kg} / \mathrm{m}^{2}($ mean $\pm \mathrm{SD})$. Median age at $\mathrm{CD}$ diagnosis was 30.0 years, while a median of 2.3 years had elapsed from diagnosis to enrollment. Involvement of both small and large intestine was reported in $65.2 \%$ of the patients. Arthralgia was reported in $45.5 \%$ and other EIMs in $27.3 \%$ of the patients. Up to the time of enrollment, $24.2 \%$ of participants had undergone a total of 26 surgical procedures since their diagnosis, including colectomy in 6 patients (Table 1).

Prior to the treatment switch, and in particular a median of 5 days prior to the switch, a total of $84.8 \%$ of the patients had undergone assessment of CRP levels (median: $13.6 \mathrm{mg} / \mathrm{L}$; interquartile range [IQR]: 6.0-53.7), while $71.2 \%$ had undergone assessment of ESR a median of 9 days prior to treatment switch (median ESR: $9.0 \mathrm{~mm} / \mathrm{h}$; IQR: 1.0-23.0). Additionally, $63.6 \%$ of the patients underwent endoscopic examination and in $40.5 \%$ of these the CD endoscopic index of severity (CDEIS) was estimated (median score: 26.0; IQR: 18.0-

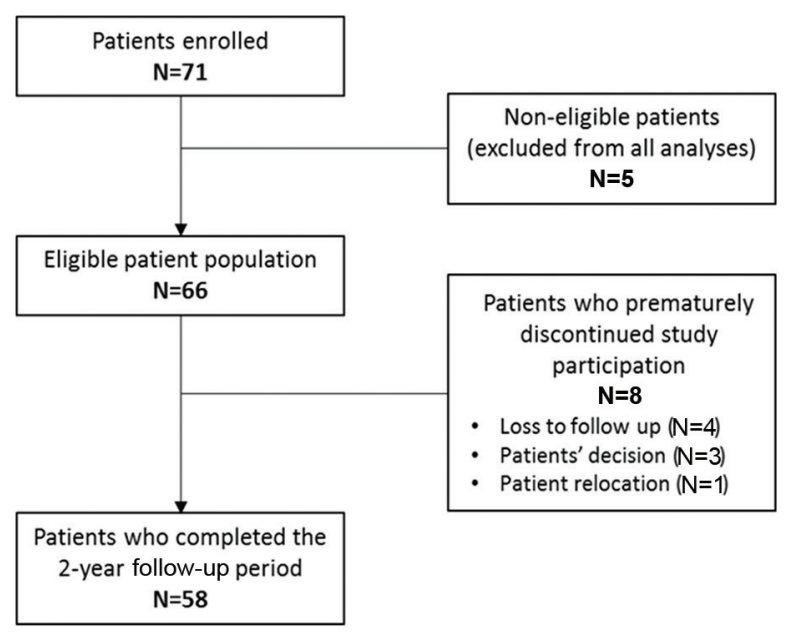

Figure 1 Patient flowchart
31.0) (Table 1). According to the CDAI, assessed for all patients at the time of treatment switch, $66.7 \%$ (95\%CI 54.0-77.8\%) of the patients had "mild" disease, 30.3\% (95\%CI 19.6-42.9\%) "moderate-to-severe", and 3.0\% (95\%CI 0.4-10.5\%) "severe" disease activity. Among the patient characteristics reported in Table 1, no statistically significant differences were noted between patients with "mild" and those with "moderate-tosevere" disease activity, apart from patient distribution in BMI categories. Specifically, binary logistic regression demonstrated that patients with "moderate-to-severe" disease activity were 4.7 times more likely than those with "mild" disease activity to have a $\mathrm{BMI}<25 \mathrm{~kg} / \mathrm{m}^{2}$ at enrollment (odds ratio $4.72,95 \% \mathrm{CI}$ 1.21-18.46; $\mathrm{P}=0.026)$.

\section{Therapeutic modalities}

All patients had been treated previously and $89.4 \%$ had received a CD-related treatment within the 10 -week time interval prior to enrollment. This "immediately prior" CD-related treatment consisted of, in order of descending frequency, 5-aminosalicylic acid (5-ASA), corticosteroids, azathioprine/6-mercaptopurine, adalimumab, methotrexate and infliximab, in $54.5 \%, 45.5 \%, 40.9 \%, 7.6 \%, 4.5 \%$ and $3.0 \%$ of patients, respectively. The respective medication frequencies in the subpopulations, according to their disease severity, are displayed in Fig. 2B,C.

Following enrollment (when the physician decided on the treatment switch) the profile of the patients' treatment regimen changed substantially: the most common treatments among the overall population were infliximab (74.2\%), azathioprine/6-mercaptopurine (45.5\%) and 5-ASA (40.9\%). Likewise, at the end of the study (104 weeks), 74.1\% were receiving infliximab, $29.3 \%$ azathioprine/6-mercaptopurine and $29.3 \%$ 5-ASA, while $6.9 \%$ were not receiving any treatment (Fig. 2A). Treatments received at the time of the treatment switch, and at 30, 54 and 104 weeks post-enrollment in the overall population, and in the subpopulations with "mild" and "moderate-to-severe" disease activity are depicted in Fig. 2B,C.

More than half of the overall population (37/66 or $56.1 \%)$ was corticosteroid-free during the entire observation period, compared to $21.2 \%(14 / 66)$ prior to enrollment. In particular, $36.4 \%$ of the patients receiving corticosteroids prior to enrollment switched to being corticosteroid-free during the entire observation period, while only one of those who were corticosteroid-free prior to enrollment (1.5\%) received corticosteroids during the study. The proportion of corticosteroid-free patients during the study did not differ between patients with "mild" (26/44 or 59.1\%) and "moderateto-severe" $(11 / 20$ or $55.0 \%)$ disease activity $(\mathrm{P}=0.790)$. The mean percentage corticosteroid-free period was $80.2 \%$ in the overall population of patients who had received corticosteroids at some time during the study $(\mathrm{n}=28)$, and $78.8 \%, 79.9 \%$ and $93.7 \%$ among the respective subpopulations with "mild" $(\mathrm{n}=18)$, "moderate-to-severe" $(\mathrm{n}=8)$, and "severe" $(\mathrm{n}=2)$ disease activity. 
A

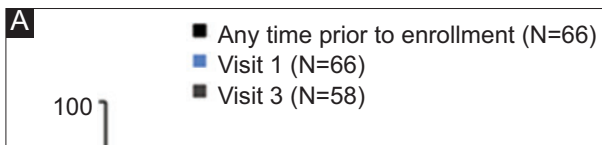

- At treatment switch $(\mathrm{N}=66)$

= Visit $2(\mathrm{~N}=61)$

Visit $2(\mathrm{~N}=58)$

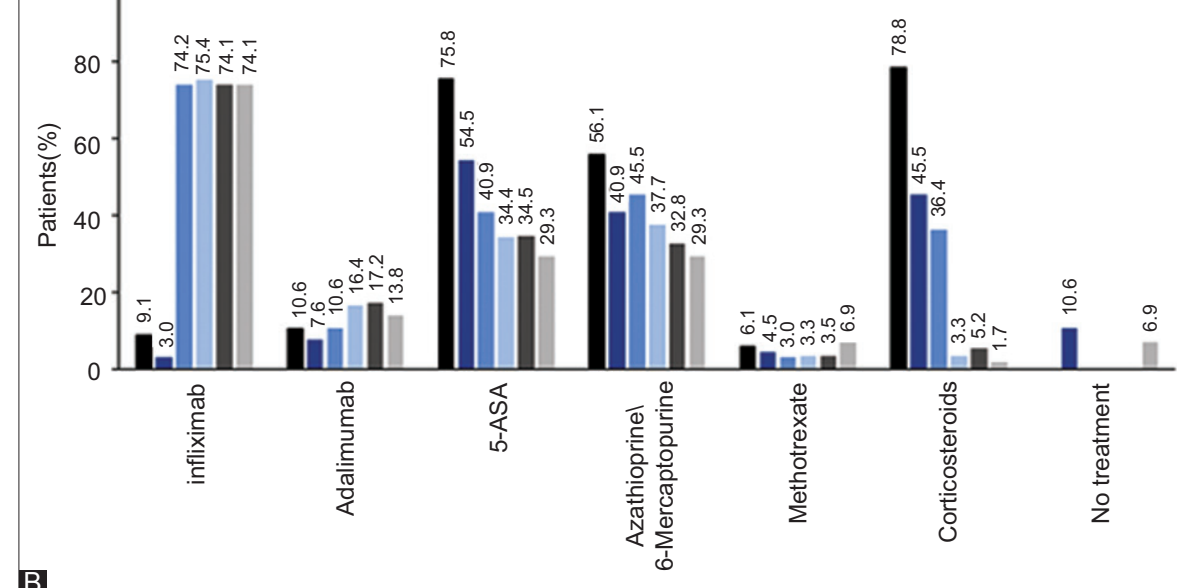

B

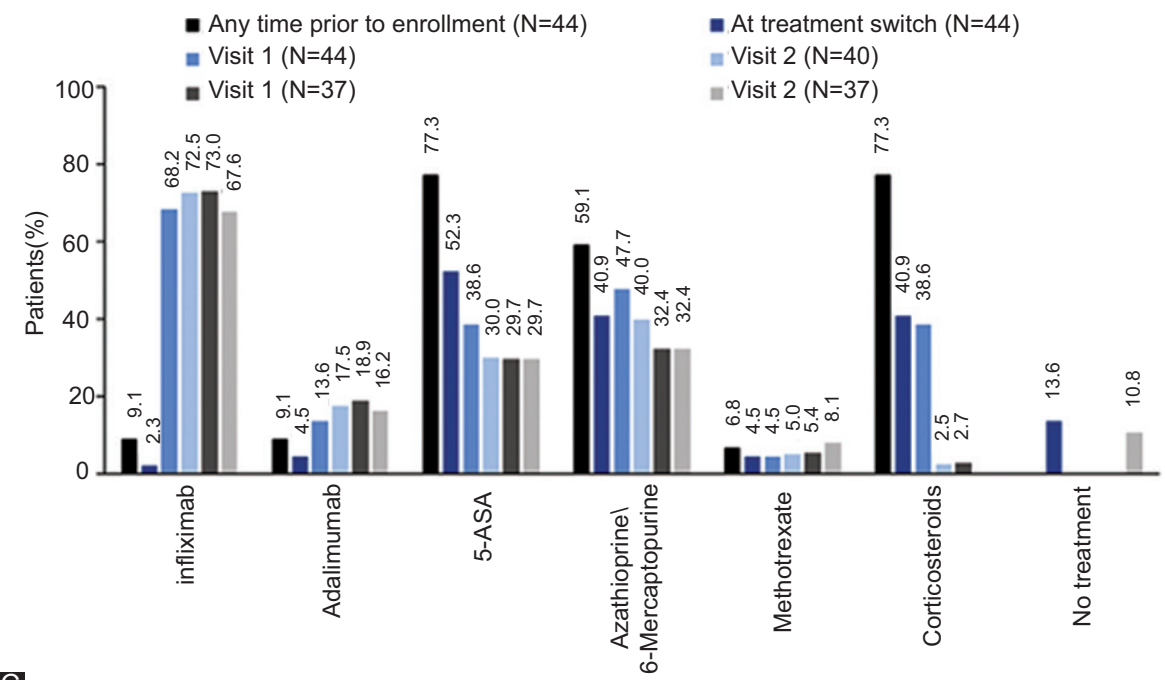

C

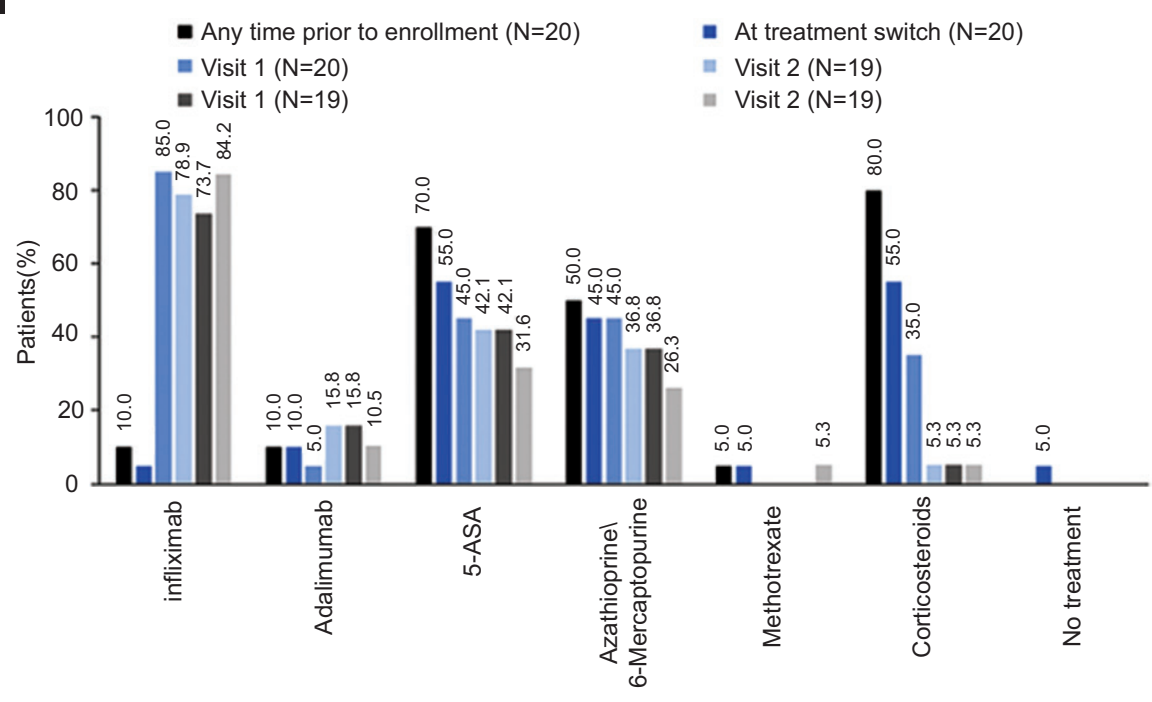

Figure 2 Crohn's disease treatment at any time prior to enrollment, immediately prior to enrollment (i.e., at treatment switch), and throughout the study observation period. In (A) the overall population, in (B) subpopulation with "mild" (CDAI $<220)$, and in (C) subpopulation with "moderateto-severe" (220 $\leq$ CDAI $\leq 450)$ disease activity. Visits occurred on Week 0 (Visit 1; enrollment), and at 30 (Visit 2), 54 (Visit 3), and 104 (Visit 4) weeks post-enrollment. $\mathrm{N}$, denotes patients with available data attending the respective study visit 
Table 1 Patients' sociodemographic, anthropometric and clinical characteristics

\begin{tabular}{|c|c|c|c|c|c|}
\hline Patient characteristics & $\begin{array}{l}\text { Overall } \\
\text { population } \\
\mathrm{N}=66\end{array}$ & $\begin{array}{c}\text { "Mild" } \\
\text { CDAI }<220 \\
\mathrm{~N}=44\end{array}$ & $\begin{array}{c}\text { "Moderate-to-severe" } \\
220 \leq \mathrm{CDAI} \leq 450 \\
\mathrm{~N}=20\end{array}$ & $\begin{array}{c}\text { "Severe" } \\
\text { CDAI }>450 \\
\mathrm{~N}=2\end{array}$ & $\begin{array}{c}\text { P-value; } \\
\text { "Mild" vs. } \\
\text { "Moderate-to-severe" }\end{array}$ \\
\hline Sex & & & & & 0.224 \\
\hline Male, n (\%) & $37(56.1)$ & $27(61.4)$ & $9(45.0)$ & $1(50.0)$ & \\
\hline Female, n (\%) & $29(43.9)$ & $17(38.6)$ & $11(55.0)$ & $1(50.0)$ & \\
\hline $\begin{array}{l}\text { Age at enrollment (years), } \\
\text { median (IQR) }\end{array}$ & $35.8(26.4,44.4)$ & $37.8(27.9,47.4)$ & $29.1(24.2,44.3)$ & $39.6(36.7,42.6)$ & 0.205 \\
\hline $\begin{array}{l}\text { Age at Crohn's disease } \\
\text { diagnosis (years), median (IQR) }\end{array}$ & $30.0(22.0,38.0)$ & $31.5(23.0,38.5)$ & $26.0(20.5,30.0)$ & $37.5(36.0,39.0)$ & 0.082 \\
\hline $\begin{array}{l}\text { Time elapsed from diagnosis } \\
\text { to enrollment (years), } \\
\text { median (IQR) }\end{array}$ & $2.3(0.7,7.9)$ & $2.4(0.9,7.9)$ & $1.4(0.2,14.0)$ & $2.1(0.7,3.6)$ & 0.393 \\
\hline BMI, mean (SD) & $23.2(3.9)$ & $23.8(3.9)$ & $22.0(3.9)$ & $23.7(5.6)$ & 0.102 \\
\hline \multicolumn{6}{|l|}{ BMI category, n (\%) } \\
\hline $\begin{array}{l}\text { Underweight or } \\
\text { Normal }\left(\mathrm{BMI}<25 \mathrm{~kg} / \mathrm{m}^{2}\right)\end{array}$ & $42(63.6)$ & $24(54.5)$ & $17(85.0)$ & $1(50.0)$ & $0.026^{\mathrm{d}}$ \\
\hline $\begin{array}{l}\text { Overweight or } \\
\text { Obese }\left(\mathrm{BMI} \geq 25 \mathrm{~kg} / \mathrm{m}^{2}\right)\end{array}$ & $24(36.4)$ & $20(45.5)$ & $3(15.0)$ & $1(50.0)$ & \\
\hline Current smokers, n (\%) & $37(56.1)$ & $25(56.8)$ & $11(55.0)$ & $1(50.0)$ & 0.897 \\
\hline Non-smokers, n (\%) & $18(27.3)$ & $11(25.0)$ & $6(30.0)$ & $1(50.0)$ & \\
\hline Ex-smokers, n (\%) & $11(16.7)$ & $8(18.2)$ & $3(15.0)$ & - & \\
\hline \multicolumn{6}{|l|}{ Primary disease site, $\mathrm{n}(\%)$} \\
\hline Both small and large intestine & $43(65.2)$ & $28(63.6)$ & $14(70.0)$ & $1(50.0)$ & 0.922 \\
\hline Small intestine & $13(19.7)$ & $9(20.5)$ & $4(20.0)$ & - & \\
\hline Large intestine & $10(15.2)$ & $7(15.9)$ & $2(10.0)$ & $1(50.0)$ & \\
\hline $\begin{array}{l}\text { Extraintestinal manifestations at } \\
\text { enrollment including arthralgia, } \\
\mathrm{n}(\%)\end{array}$ & $34(51.5)$ & $21(47.7)$ & $12(60.0)$ & $1(50.0)$ & 0.425 \\
\hline $\begin{array}{l}\text { Extraintestinal manifestations at } \\
\text { enrollment excluding arthralgia, } \\
\mathrm{n}(\%)\end{array}$ & $18(27.3)$ & $10(22.7)$ & $8(40.0)$ & - & 0.230 \\
\hline Arthritis & $10(15.2)$ & $8(18.2)$ & $2(10.0)$ & - & \\
\hline Oral aphthae & $3(4.5)$ & $1(2.3)$ & $2(10.0)$ & - & \\
\hline Sacroilitis & $3(4.5)$ & $1(2.3)$ & $2(10.0)$ & - & \\
\hline Episcleritis & $2(3.0)$ & $1(2.3)$ & $1(5.0)$ & - & \\
\hline Erythema nodosum & $2(3.0)$ & - & $2(10.0)$ & - & \\
\hline $\begin{array}{l}\text { Perianal abscess, perianal } \\
\text { fistula }\end{array}$ & $2(3.0)$ & $1(2.3)$ & $1(5.0)$ & - & \\
\hline Ankylosing spondylitis & $1(1.5)$ & - & $1(5.0)$ & - & \\
\hline Iridocyclitis & $1(1.5)$ & - & $1(5.0)$ & - & \\
\hline CDEIS score, median (IQR) & $\begin{array}{c}26.0(18.0,31.0) \\
\mathrm{n}=17\end{array}$ & $\begin{array}{c}18.0(10.0,33.0) \\
\mathrm{n}=11\end{array}$ & $\begin{array}{c}29.0(26.0,31.0) \\
\mathrm{n}=6\end{array}$ & - & 0.077 \\
\hline $\begin{array}{l}\text { Patients with at least one } \\
\text { surgical procedure prior to } \\
\text { enrollment }\end{array}$ & $16(24.2)$ & $9(20.5)$ & $7(35.0)$ & - & 0.383 \\
\hline $\begin{array}{l}\text { Colectomy (with or without } \\
\text { small intestinal resection or } \\
\text { abscess/incisional drainage) }\end{array}$ & $6(9.1)$ & $4(9.1)$ & $2(10.0)$ & - & N/A \\
\hline
\end{tabular}


Table 1 Continued

\begin{tabular}{|c|c|c|c|c|c|}
\hline Patient characteristics & $\begin{array}{c}\text { Overall } \\
\text { population } \\
\mathrm{N}=66\end{array}$ & $\begin{array}{c}\text { "Mild" } \\
\text { CDAI }<220 \\
\mathrm{~N}=44\end{array}$ & $\begin{array}{c}\text { "Moderate-to-severe" } \\
220 \leq \mathrm{CDAI} \leq 450 \\
\mathrm{~N}=20\end{array}$ & $\begin{array}{c}\text { "Severe" } \\
\text { CDAI }>450 \\
\mathrm{~N}=2\end{array}$ & $\begin{array}{c}\text { P-value; } \\
\text { "Mild" vs. } \\
\text { "Moderate-to-severe" }\end{array}$ \\
\hline $\begin{array}{l}\text { Small intestinal } \\
\text { resection (with or } \\
\text { without abscess/incisional } \\
\text { drainage) without } \\
\text { colectomy }\end{array}$ & $3(4.5)$ & $1(2.3)$ & $2(10.0)$ & - & N/A \\
\hline $\begin{array}{l}\text { Abscess/incisional } \\
\text { drainage (without } \\
\text { colectomy or small } \\
\text { intestinal resection) }\end{array}$ & $7(10.6)$ & $4(9.1)$ & $3(15.0)$ & - & N/A \\
\hline $\begin{array}{l}\text { Patients with at least one } \\
\text { comorbid condition at } \\
\text { enrollment }^{\mathrm{a}}\end{array}$ & $28(42.4)$ & $20(45.5)$ & $8(40.0)$ & - & N/A \\
\hline
\end{tabular}

\section{CDAl score during the study}

The baseline CDAI score in the overall population (median: 174.5 points) decreased by a median of $142.0,145.5$ and 146.0 points at 30,54 and 104 weeks $(\mathrm{P}<0.001)$, respectively, in the overall population. Statistically significant decreases from baseline were also noted in the CDAI score for patients with "mild" or "moderate-to-severe" disease activity $(\mathrm{P}<0.001)$ (Table 2). CDAI scores remained significantly different between patients with "mild" and those with "moderateto-severe" disease activity at 30 weeks $(\mathrm{P}=0.009)$, but not at 54 and 104 weeks post-enrollment (Table 2). At 30, 54 and 104 weeks post-enrollment the proportions of patients with a CDAI score $<220$ by intention-to-treat analysis were $85 \%$ (56/66), 71\% (47/66), and 71\% (47/66), while by observation the rates were $100 \%(56 / 56), 97.9 \%(47 / 48)$, and $100 \%$ (47/47), respectively. The respective disease remission rates, as indicated by a CDAI $<150$, were $100 \%$ (56/56), $93.8 \%$ (45/48), and $95.7 \%(45 / 47)$.

\section{CRP levels during the study}

The baseline CRP levels of the overall population (median: $13.6 \mathrm{mg} / \mathrm{L}$ ) significantly decreased by a median of $5.1(\mathrm{P}<0.001), 6.6(\mathrm{P}<0.001)$ and $10.3 \mathrm{mg} / \mathrm{L}(\mathrm{P}<0.001)$ at a median of $7.5,12.7$ and 24.2 months post-baseline, respectively (corresponding to assessments recorded at Visits 2, 3, and 4). Statistically significantly decreases in baseline CRP levels were also noted for patients with "mild" (median decreases of $5.3[\mathrm{P}<0.001], 4.3[\mathrm{P}<0.001]$ and $7.9 \mathrm{mg} / \mathrm{L}[\mathrm{P}=0.005]$ at Visits 2,3 , and 4, respectively) and "moderate-to-severe" disease activity (median decreases of $2.3[\mathrm{P}=0.024], 10.5[\mathrm{P}=0.024]$ and $11.5 \mathrm{mg} / \mathrm{L}[\mathrm{P}<0.001]$ at Visits 2, 3, and 4, respectively) (Table 2).

\section{CD-related surgeries}

During the first year of observation, corresponding to a total of 63.2 patient-years at risk, five CD-related surgeries (colectomy, abscess drainage, ileectomy, incisional drainage, and intestinal anastomosis) were reported among 6\% (4/66) of the patients, yielding a 1-year CD-related surgery incidence rate of 0.08 per patient-year in the overall population. Likewise, during the second year of observation, 1 patient was reported to have undergone CD-related surgery (colectomy). Based on the above, corresponding to a total of 119.8 patient-years at risk, six CD-related surgeries were reported among 7.5\% patients $(5 / 66)$ of the overall population, yielding a 2 -year CD-related surgery incidence rate of 0.05 per patient-year. The 1- and 2-year surgery rates were 0.02 and 0.03 for patients with "mild" and 0.20 and 0.11 patient-years for patients with "moderate-to-severe" disease activity, respectively. None of the patients with "severe" disease activity underwent any surgery during the study period.

\section{Hospitalization rates}

The 1 -year hospitalization rates were 0.13 per patient-year among patients receiving "regimens containing anti-TNF biologics without immunosuppressives" $(n=29), 0.27$ for those receiving "regimens containing anti-TNF biologics with immunosuppressives" $(\mathrm{n}=25)$ and 0.85 for "other regimens without anti-TNF biologics" $(\mathrm{n}=8)$; the 2 -year hospitalization rates were $0.09,0.16,0.40$ per patient-year, respectively, in the three groups.

In the overall population, $19 \mathrm{CD}$-related hospitalizations with a mean duration of $14.5 \pm 15.5$ days (range: 1.0-49.0; IQR: 2.0-24.5) were reported by $19.4 \%(12 / 62)$ of patients during the 2 -year study observation period. The main reason for hospitalizations was reported to be disease relapse/complications/progression 
Table 2 CDAI scores and CRP levels at baseline and at all post-baseline time-points, and changes in CDAI score and CRP levels from baseline in the overall population and according to disease activity

\begin{tabular}{|c|c|c|c|c|c|c|c|c|c|}
\hline \multirow{2}{*}{$\begin{array}{l}\text { CDAI } \\
\text { scores and } \\
\text { CRP levels }\end{array}$} & \multicolumn{2}{|c|}{ Overall population } & \multicolumn{2}{|c|}{$\begin{array}{c}\text { "Mild" } \\
\text { CDAI <220 }\end{array}$} & \multicolumn{2}{|c|}{$\begin{array}{l}\text { "Moderate-to-severe" } \\
220 \leq \mathrm{CDAI} \leq 450\end{array}$} & \multicolumn{2}{|r|}{$\begin{array}{l}\text { "Severe" } \\
\text { CDAI }>450\end{array}$} & \multirow{2}{*}{$\begin{array}{c}\text { P-value; } \\
\text { "Mild" vs. } \\
\text { "Moderate-to-severe" }\end{array}$} \\
\hline & $\mathrm{n}$ & $\begin{array}{l}\text { Median } \\
(\mathrm{IQR})\end{array}$ & $\mathrm{n}$ & $\begin{array}{c}\text { Median } \\
\text { (IQR) }\end{array}$ & $\mathrm{n}$ & $\begin{array}{l}\text { Median } \\
(\mathrm{IQR})\end{array}$ & $\mathrm{n}$ & $\begin{array}{l}\text { Median } \\
(\mathrm{IQR})\end{array}$ & \\
\hline $\begin{array}{l}\text { Baseline CDAI } \\
\text { score }\end{array}$ & 66 & $\begin{array}{c}174.5 \\
(140.0,251.0)\end{array}$ & 44 & $\begin{array}{c}159.0 \\
(98.5,174.5)\end{array}$ & 20 & $\begin{array}{c}277.5 \\
(248.0,317.0)\end{array}$ & 2 & $\begin{array}{c}491.0 \\
(455.0,527.0)\end{array}$ & $\mathrm{n} / \mathrm{a}$ \\
\hline $\begin{array}{l}\text { CDAI score at } \\
\text { Visit } 2\end{array}$ & 56 & $\begin{array}{c}39.5 \\
(23.5,68.5)\end{array}$ & 37 & $\begin{array}{c}36.0 \\
(19.0,44.0)\end{array}$ & 17 & $\begin{array}{c}52.0 \\
(40.0,89.0)\end{array}$ & 2 & $\begin{array}{c}72.0 \\
(70.0,74.0)\end{array}$ & 0.009 \\
\hline $\begin{array}{l}\text { CDAI score at } \\
\text { Visit } 3\end{array}$ & 48 & $\begin{array}{c}41.0 \\
(17.5,71.5)\end{array}$ & 31 & $\begin{array}{c}36.0 \\
(13.0,70.0)\end{array}$ & 15 & $\begin{array}{c}42.0 \\
(25.0,72.0)\end{array}$ & 2 & $\begin{array}{c}105.0 \\
(100.0,110.0)\end{array}$ & 0.542 \\
\hline $\begin{array}{l}\text { CDAI score at } \\
\text { Visit } 4\end{array}$ & 47 & $\begin{array}{c}35.0 \\
(10.0,57.0)\end{array}$ & 29 & $\begin{array}{c}35.0 \\
(10.0,38.0)\end{array}$ & 16 & $\begin{array}{c}44.5 \\
(17.5,98.5)\end{array}$ & 2 & $\begin{array}{c}16.5 \\
(10.0,23.0)\end{array}$ & 0.148 \\
\hline $\begin{array}{l}\text { CDAI at Visit } \\
2-\mathrm{CDAI} \text { at } \\
\text { Baseline }\end{array}$ & 56 & $\begin{array}{c}-142.0 \\
(-176.5,-94.5)\end{array}$ & 37 & $\begin{array}{c}-125.0 \\
(-148.0,-61.0)\end{array}$ & 17 & $\begin{array}{c}-230.0 \\
(-262.0,-169.0)\end{array}$ & 2 & $\begin{array}{c}-419.0 \\
(-453.0,-385.0)\end{array}$ & $<0.001$ \\
\hline $\begin{array}{l}\text { CDAI at Visit } \\
3 \text { - CDAI at } \\
\text { Baseline }\end{array}$ & 48 & $\begin{array}{c}-145.5 \\
(-206.5,-84.0)\end{array}$ & 31 & $\begin{array}{c}-122.0 \\
(-148.0,-25.0)\end{array}$ & 15 & $\begin{array}{c}-230.0 \\
(-268.0,-182.0)\end{array}$ & 2 & $\begin{array}{c}-386.0 \\
(-417.0,-355.0)\end{array}$ & $<0.001$ \\
\hline $\begin{array}{l}\text { CDAI at Visit } \\
4-\mathrm{CDAI} \text { at } \\
\text { Baseline }\end{array}$ & 47 & $\begin{array}{c}-146.0 \\
(-213.0,-110.0)\end{array}$ & 29 & $\begin{array}{c}-135.0 \\
(-148.0,-91.0)\end{array}$ & 16 & $\begin{array}{c}-227.0 \\
(-256.5,-160.0)\end{array}$ & 2 & $\begin{array}{c}-474.5 \\
(-504.0,-445.0)\end{array}$ & 0.001 \\
\hline $\begin{array}{l}\text { Baseline CRP } \\
\text { levels, mg/L }\end{array}$ & 56 & $\begin{array}{c}13.6 \\
(6.0,53.7)\end{array}$ & 35 & $\begin{array}{c}12.1 \\
(5.4,35.0)\end{array}$ & 19 & $\begin{array}{c}14.5 \\
(8.7,59.2)\end{array}$ & 2 & $\begin{array}{c}103.3 \\
(2.6,204.0)\end{array}$ & 0.409 \\
\hline $\begin{array}{l}\text { CRP levels at } \\
\text { Visit 2, mg/L }\end{array}$ & 41 & $\begin{array}{c}4.4 \\
(1.7,9.0)\end{array}$ & 28 & $\begin{array}{c}3.4 \\
(1.1,9.1)\end{array}$ & 11 & $\begin{array}{c}7.0 \\
(2.8,9.0)\end{array}$ & 2 & $\begin{array}{c}3.7 \\
(3.0,4.4)\end{array}$ & 0.426 \\
\hline $\begin{array}{l}\text { CRP levels at } \\
\text { Visit 3, mg/L }\end{array}$ & 43 & $\begin{array}{c}3.5 \\
(1.4,8.3)\end{array}$ & 26 & $\begin{array}{c}3.5 \\
(1.4,9.9)\end{array}$ & 15 & $\begin{array}{c}3.5 \\
(2.0,7.8)\end{array}$ & 2 & $\begin{array}{c}1.6 \\
(1.2,2.0)\end{array}$ & 0.616 \\
\hline $\begin{array}{l}\text { CRP levels at } \\
\text { Visit } 4, \mathrm{mg} / \mathrm{L}\end{array}$ & 42 & $\begin{array}{c}3.0 \\
(1.1,6.0)\end{array}$ & 24 & $\begin{array}{c}2.7 \\
(1.1,8.6)\end{array}$ & 16 & $\begin{array}{c}4.1 \\
(1.0,8.0)\end{array}$ & 2 & $\begin{array}{c}2.7 \\
(2.0,3.3)\end{array}$ & 0.858 \\
\hline $\begin{array}{l}\text { CRP at Visit } \\
2-\mathrm{CRP} \text { at } \\
\text { Baseline, } \mathrm{mg} / \mathrm{L}\end{array}$ & 36 & $\begin{array}{c}-5.1 \\
(-24.2,-2.0)\end{array}$ & 23 & $\begin{array}{c}-5.3 \\
(-21.5,-3.1)\end{array}$ & 11 & $\begin{array}{c}-2.3 \\
(-47.0,-0.6)\end{array}$ & 2 & $\begin{array}{c}-99.6 \\
(-199.6,0.4)\end{array}$ & 0.418 \\
\hline $\begin{array}{l}\text { CRP at Visit } \\
3-\mathrm{CRP} \text { at } \\
\text { Baseline, } \mathrm{mg} / \mathrm{L}\end{array}$ & 38 & $\begin{array}{c}-6.6 \\
(-20.8,-1.1)\end{array}$ & 21 & $\begin{array}{c}-4.3 \\
(-16.4,-1.7)\end{array}$ & 15 & $\begin{array}{c}-10.5 \\
(-27.6,0.6)\end{array}$ & 2 & $\begin{array}{c}-101.7 \\
(-202.8,-0.6)\end{array}$ & 0.860 \\
\hline $\begin{array}{l}\text { CRP at Visit } \\
4-\mathrm{CRP} \text { at } \\
\text { Baseline, } \mathrm{mg} / \mathrm{L}\end{array}$ & 36 & $\begin{array}{c}-10.3 \\
(-22.1,-2.2)\end{array}$ & 18 & $\begin{array}{c}-7.9 \\
(-20.3,-1.3)\end{array}$ & 16 & $\begin{array}{c}-11.5 \\
(-38.2,-3.9)\end{array}$ & 2 & $\begin{array}{c}-100.6 \\
(-200.7,-0.6)\end{array}$ & 0.352 \\
\hline
\end{tabular}

CDAI, Crohn's disease activity index; IQR, interquartile range; CRP, C-reactive protein

$(13 / 19 ; 68.4 \%)$, while $10.5 \%$ of hospitalizations were due to perianal disease, $10.5 \%$ were for scheduled procedures and the remaining $10.5 \%$ for other reasons. Ten hospitalizations were reported by $14.6 \%(6 / 41)$ of patients with "mild" disease activity and the remaining 9 hospitalizations by $31.6 \%(6 / 19)$ of patients with "moderate-to-severe" disease activity. The 1- and 2-year hospitalization rates were 0.27 and 0.16 per patient-year in the overall population ( 0.22 and 0.13 among patients with "mild"; 0.40 and 0.24 for patients with "moderate-to-severe" disease activity).

Univariate regression analysis revealed that the probability of being hospitalized was lower among patients with a $\mathrm{BMI} \geq 25 \mathrm{~kg} / \mathrm{m}^{2}$ compared to patients with $\mathrm{BMI}<25 \mathrm{~kg} / \mathrm{m}^{2}$ (incidence rate ratio: $0.19,95 \% \mathrm{CI}$ 0.04-0.96; $\mathrm{P}=0.04$ ). Age $(\mathrm{P}=0.90)$, sex $(\mathrm{P}=0.85)$, time elapsed since $\mathrm{CD}$ diagnosis $(\mathrm{P}=0.51)$, disease location ( $\mathrm{p}=0.67)$, presence of extra-intestinal manifestation $(\mathrm{s})(\mathrm{P}=0.30)$, treatment regimen containing antiTNF biologics prior to enrollment $(\mathrm{P}=0.14)$, and CDAI baseline score $(\mathrm{P}=0.30)$ were not predictors of hospitalization (Table 3 ).

\section{Discussion}

The present prospective study of adult CD patients $(<65$ years of age), inadequately controlled with their current 
Table 3 Univariate regression of potential factors affecting the hospitalization incidence rate

\begin{tabular}{|c|c|c|c|c|}
\hline \multirow[t]{2}{*}{ Parameters } & \multirow[t]{2}{*}{ IRR } & \multicolumn{2}{|c|}{ 95\% confidence interval } & \multirow[t]{2}{*}{ P-value } \\
\hline & & Lower limit & Upper limit & \\
\hline Age (years) & 1.00 & 0.96 & 1.05 & 0.900 \\
\hline \multicolumn{5}{|l|}{ Sex } \\
\hline "Female" vs. "Male" & 0.88 & 0.25 & 3.13 & 0.848 \\
\hline Time elapsed since CD diagnosis (years) & 0.97 & 0.87 & 1.07 & 0.512 \\
\hline \multicolumn{5}{|l|}{ BMI at enrollment } \\
\hline "BMI $\geq 25 \mathrm{Kg} / \mathrm{m}^{2}$ ” vs. "BMI<25 Kg/m $\mathrm{m}^{2}$ " & 0.19 & 0.04 & 0.96 & 0.045 \\
\hline \multicolumn{5}{|l|}{ Primary disease site } \\
\hline "Both" vs. "large" or "small" intestine" & 0.76 & 0.21 & 2.74 & 0.670 \\
\hline \multicolumn{5}{|c|}{$\begin{array}{l}\text { Presence of extraintestinal manifestation (s) at enrollment including } \\
\text { arthralgia }\end{array}$} \\
\hline Yes vs. No & 0.51 & 0.15 & 1.79 & 0.295 \\
\hline \multicolumn{5}{|c|}{$\begin{array}{l}\text { Regimen containing anti-TNF biologics at the time of the treatment } \\
\text { switch }\end{array}$} \\
\hline Yes vs. No & 0.32 & 0.07 & 1.46 & 0.141 \\
\hline \multicolumn{5}{|l|}{ CDAI baseline score } \\
\hline $\begin{array}{l}C D A I<220 \text { vs. } \\
220 \leq C D A I \leq 450\end{array}$ & 0.52 & 0.14 & 1.82 & 0.304 \\
\hline
\end{tabular}

IRR, incidence rate ratio; $C D$, Crohn's disease; BMI, body mass index; TNF, tumor necrosis factor; CDAI, Crohn's disease activity index

therapy according to their physician's medical judgment, conducted in nine referral centers in Greece, is one of the few published studies of such design to be conducted until now. The results showed that, when participating physicians decided on a treatment switch, according to their medical judgement and clinical assessments in routine practice, two thirds of the patients presented with "mild" disease activity, while $30.3 \%$ and only $3.0 \%$ had "moderate-to-severe" and "severe" disease activity, respectively, according to their CDAI scores. It should be clarified at this point that the inclusion of only 66 patients, instead of the 100 patients initially estimated, limits the initially assumed precision of $7 \%$ in order to prove the hypothesis of a higher percentage of mild disease in Greek CD patients. Nevertheless, this does not limit the importance of our observations, which suggest that neither physicians nor patients are satisfied with mild disease activity, but prefer to pursue an alternate treatment that may yield complete remission. In addition, it should be underlined that $77.3 \%$ of patients categorized at enrollment as having "mild disease" according to their CDAI were being actively treated with corticosteroids, a fact which, alongside other clinical assessments, undoubtedly influenced the decision to switch their therapy. The design of this study did not permit an accurate evaluation of the patients' initial disease activity, although they were all inadequately controlled under treatment. This probably indicates that the patients had more severe activity during their initial presentation and that their treatment at enrollment was only partially successful-a situation that frequently occurs in real life-leading to a treatment switch.
In addition, it partially explains the high percentage of patients with "mild" disease activity at enrollment. Ileocolonic disease was observed in a relatively high proportion of our study population (65.2\%). Interestingly, no association was observed between disease location and severity, with ileocolonic disease being present in $63.6 \%$ of patients with "mild" and $70.0 \%$ of those with "moderate-to-severe" disease activity. In a Greek study that collected data from 1001 CD patients, $65 \%$ of whom had active disease, the prevalence of ileocolonic involvement was reported to be $49.3 \%$ [6]; this suggests a higher rate of ileocolonic involvement among the patients of our study, considering that disease location is considered to be relatively stable (estimated change of $10-15 \%$ over approximately 10 -year follow up) [12].

At enrollment, EIMs (including self-reported arthralgias) were present in $51.5 \%$ of our overall study population and did not differ between patients with "mild" (47.7\%) and "moderateto-severe" disease activity (60.0\%). In a large retrospective study, including $1001 \mathrm{CD}$ patients mainly with active disease followed in 8 tertiary hospitals throughout Greece, published after the completion of the present study, $40.6 \%$ of the patients reported EIMs [6]. EIM rates in the present study are quite similar to those of a pan-European cohort of CD patients with a Harvey Bradshaw Index of at least 7 at enrollment, of whom 52.6\% (497/945) had EIMs [13]. Consistently with the earlier Greek study [6], the most commonly reported EIMs in the present study were arthralgias (45.5\%), followed by arthritis (15.2\%). The higher prevalence of arthralgias in the present study may in part be explained by the way they were recorded, 
based on patients' self-report, and possibly by the fact that at the time of enrollment all patients were considered to be inadequately controlled.

Prior to the treatment switch, only $10.6 \%$ of the overall population had been exposed to anti-TNFs. Treatment switch led to anti-TNF use in $84.8 \%$ of patients (infliximab in $74.2 \%$ and adalimumab in $10.6 \%$ ), a proportion which remained fairly stable through the study observation period $(91.3 \%$ and $87.9 \%$ among patients with available data at the $54^{\text {th }}$ and $104^{\text {th }}$ post-enrollment weeks). Use of anti-TNFs was high, not only among patients with "moderate-to-severe" disease at the time of treatment switch, but also among those with "mild" disease, which may be rationalized by the fact that among these patients corticosteroid use was high, the available CDEIS scorings indicated severe disease, and a high proportion of the study population had poor prognostic factors, including ileal or ileocolonic involvement, CD diagnosis at a young age, and current smoking. According to ECCO guidelines, treatment with thiopurines and/or biologics should be considered for patients with at least two poor prognostic factors [1].

Regarding the impact of anti-TNFs on corticosteroid dependence in our study, we observed that, while only $21.2 \%$ of the study population were corticosteroid-free prior to enrollment, more than half $(56.1 \%)$ were corticosteroid-free throughout the whole study observation period following

\section{Summary Box}

\section{What is already known:}

- Outcomes in patients with Crohn's disease (CD) under conventional treatment are suboptimal

- A large proportion remain under corticosteroids and/or are referred for surgery

- Physicians' behavior has shifted towards faster access to more efficacious treatments, especially biologic agents

- Data concerning the routine care management of CD patients in Greece are scarce

\section{What the new findings are:}

- Many CD patients in Greece with suboptimal results under conventional therapies present with mild disease

- Switching to an anti-tumor necrosis factor (TNF) agent is the option preferred by gastrointestinal specialists in order to improve a patient's outcome

- Under anti-TNFs there is substantial improvement, independently of the initial disease activity score (mild or moderate-to-severe)

- This improvement is maintained for at least two years for most patients, with little need for corticosteroid use or surgery the treatment switch. Moreover, after the treatment switch, CDAI scores and CRP levels were significantly reduced, in the overall population and in subpopulations defined by disease activity. The median CDAI scores and CRP rates did not differ between patients with "mild" and "moderate-to-severe" disease activity at 54 and 104 weeks post-enrollment; response and/or remission rates were greater than $68 \%$ at all study time-points. This underlines the effectiveness of anti-TNF medication for the induction and maintenance of remission in a large spectrum of patients [14-17]. During the study observation period following the treatment switch, the CD-related hospitalization rate was $19.4 \%$ and the surgery rate $8.1 \%$.

\section{Limitations}

One limitation of the present study is the lack of a strict definition of inadequately, or poorly controlled disease and a specified therapeutic protocol that could lead to interobserver variation. However, this study was an observational, noninterventional study and a strict therapeutic protocol would have transformed it into an interventional study, completely changing the entire scientific and regulatory approach. On the other hand, it was inherent within the study design to capture the therapeutic management strategies decided upon by physicians according to the clinical assessments and criteria they use in their routine care practice, without imposing a treatment optimization protocol or clinical assessments, thus yielding real-world data representative of the routine care practice of IBD referral centers around the country. The internal validity of the outcomes was enhanced by the implementation of appropriate source data verification and quality assurance measures.

A further limitation is that the evaluable patient population $(n=66)$ was lower than the planned sample of 100 patients. Although this numerical deviation from the initially proposed sample size compromised the initially assumed power and the estimation based on a higher percentage of mild disease in Greece, it was not expected to adversely impact the meaningfulness of the study outcomes, since this was an epidemiological study that primarily aimed to capture realworld data and analyze it descriptively, rather than to prove or reject a formal statistical hypothesis. Nevertheless, caution should be exercised in the interpretation of the statistical significance of outcomes involving a limited number of observations and the fact that the estimated sample size was not achieved.

In summary, Greek real-world data indicate that inadequately controlled adult CD patients under 65 years of age attending IBD referral centers are frequently burdened by EIMs, ileocolonic disease location, corticosteroid use and prior CD-related surgeries. The majority of uncontrolled patients are switched to anti-TNFs, mainly infliximab. Over the 2-year observation period, CDAI scores, CRP levels and corticosteroid use were reduced. Nearly all patients achieved remission for long periods during the study, while CD-related hospitalizations were reported in less than a fifth and surgeries in less than a tenth of the patient population. 


\section{Acknowledgments}

Assistance in data collection was provided by E. Zampeli, Gastroenterology Department, "Alexandra" General Hospital of Athens, I. Beintaris, Hepatogastroenterology Unit, Second Department of Internal Medicine, "Attikon" University General Hospital, Athens, K. Oikonomou, Gastroenterology Department, University General Hospital of Larissa, G. Michalopoulos, Gastroenterology Department, "Tzaneio" General Hospital of Piraeus, Piraeus, N. Mathou, Gastroenterology Department, "Konstantopouleio-Agia Olga" General Hospital of Nea Ionia, Athens.

\section{References}

1. Gomollón F, Dignass A, Annese V, et al; ECCO. $3^{\text {rd }}$ European Evidence-based Consensus on the Diagnosis and Management of Crohn's Disease 2016: Part 1: Diagnosis and Medical Management. J Crohns Colitis 2017;11:3-25.

2. Burisch J. Crohn's disease and ulcerative colitis. Occurrence, course and prognosis during the first year of disease in a European population-based inception cohort. Dan Med J 2014;61:B4778.

3. Golovics PA, Lakatos L, Mandel MD, et al. Prevalence and predictors of hospitalization in Crohn's disease in a prospective population-based inception cohort from 2000-2012. World J Gastroenterol 2015;21:7272-7280.

4. Mantzaris GJ, Viazis N, Polymeros D, Papamichael K, Bamias G, Koutroubakis IE. Clinical profiles of moderate and severe Crohn's disease patients and use of anti-tumor necrosis factor agents: Greek expert consensus guidelines. Ann Gastroenterol 2015;28:417-425.

5. Burisch J, Jess T, Martinato M, Lakatos PL; ECCO -EpiCom. The burden of inflammatory bowel disease in Europe. J Crohns Colitis 2013;7:322-337.

6. Karmiris K, Avgerinos A, Tavernaraki A, et al. Prevalence and characteristics of extra-intestinal manifestations in a large cohort of Greek patients with inflammatory bowel disease. J Crohns Colitis
2016;10:429-436.

7. Manousos ON, Koutroubakis I, Potamianos S, Roussomoustakaki M, Gourtsoyiannis N, Vlachonikolis IG. A prospective epidemiologic study of Crohn's disease in Heraklion, Crete. Incidence over a 5-year period. Scand J Gastroenterol 1996;31:599-603.

8. Archimandritis AJ, Kourtesas D, Sougioultziz S, et al. Inflammatory bowel disease in Greece-- a hospital-based clinical study of 172 consecutive patients. Med Sci Monit 2002;8:CR158-CR164.

9. Christodoulou DK, Katsanos KH, Kitsanou M, Stergiopoulou C, Hatzis J, Tsianos EV. Frequency of extraintestinal manifestations in patients with inflammatory bowel disease in Northwest Greece and review of the literature. Dig Liver Dis 2002;34:781-786.

10. Triantafillidis JK, Emmanouilidis A, Manousos O, Nicolakis D, Kogevinas M. Clinical patterns of Crohn's disease in Greece: a follow-up study of 155 cases. Digestion 2000;61:121-128.

11. Triantafillidis JK, Emmanouilidis A, Nicolakis D, et al. Surgery for Crohn's disease in Greece: a follow-up study of 79 cases. Hepatogastroenterology 2001;48:1072-1077.

12. Golovics PA, Mandel MD, Lovasz BD, Lakatos PL. Inflammatory bowel disease course in Crohn's disease: is the natural history changing? World J Gastroenterol 2014;20:3198-3207.

13. Löfberg R, Louis EV, Reinisch W, et al. Adalimumab produces clinical remission and reduces extraintestinal manifestations in Crohn's disease: results from CARE. Inflamm Bowel Dis 2012;18:1-9.

14. Hinojosa J, Gomollón F, García S, et al; Spanish Scientific Group on Crohn's Disease and Ulcerative Colitis. Efficacy and safety of short-term adalimumab treatment in patients with active Crohn's disease who lost response or showed intolerance to infliximab: a prospective, open-label, multicentre trial. Aliment Pharmacol Ther 2007;25:409-418.

15. Levesque BG, Greenberg GR, Zou G, et al. A prospective cohort study to determine the relationship between serum infliximab concentration and efficacy in patients with luminal Crohn's disease. Aliment Pharmacol Ther 2014;39:1126-1135.

16. Varma P, Paul E, Huang C, Headon B, Sparrow MP. A retrospective comparison of infliximab versus adalimumab as induction and maintenance therapy for Crohn disease. Intern Med J 2016;46:798-804.

17. Zorzi F, Zuzzi S, Onali S, et al. Efficacy and safety of infliximab and adalimumab in Crohn's disease: a single centre study. Aliment Pharmacol Ther 2012;35:1397-1407. 